\title{
Clinical examinations for professional qualification in psychiatry: the patients' views
}

\author{
Rajendra D. Persaud, Registrar, Bethlem Royal and Maudsley Hospitals, Denmark \\ Hill, London SE5 8AZ (correspondence); and CLIVE J. MeUX, Senior Registrar, \\ Bethlem Royal and Maudsley Hospitals, Monks Orchard Road, Beckenham, \\ Kent BR3 3BX
}

As part of testing candidates' abilities, patients are used in clinical examinations for professional qualifications throughout all specialties and levels of medicine. However, the patients' views on being used for these purposes have not been investigated. Examiners use the opportunity presented by candidates interviewing patients in an examination setting as part of the test of a candidate's ability in psychiatry. Psychiatric patients' experiences of such examinations may be so different from that of most clinical practice that there may be profound effects on their views of themselves, their illnesses, hospitals and of the profession itself.

One of the purposes of such examinations is to simulate as closely as possible how candidates react to the clinical problems they would meet in everyday practice. Particularly in psychiatric examinations, how closely this reality is attained would be affected by the patients' perceptions of this special situation.

While seniors frequently assess junior colleagues, patients' concerns about their doctors are almost entirely ignored in medical selection processes such as examinations. In the Royal College of Psychiatrists' Membership Examination some attempt is made to gauge how candidates relate to patients, but the patients' views of the candidate are usually unknown.

Much attention is paid to the formal organisation of clinical examinations involving patients, but this is with reference to the needs of examiners and candidates, while those of patients remain largely unassessed.

Although much has been written about preparing organisers and candidates for clinical examinations, there is little reference in the literature to patients' views of psychiatric clinical examinations. The only report found was the anecdotal comment made by McDonald et al (1988) that one lady's reaction to receiving payment for taking part was that "it was wonderful for her to be paid for someone to listen to her".

In the light of these considerations a descriptive survey of patients' views of a recent membership examination of the Royal College of Psychiatrists was attempted. It was hoped the results would be of particular interest to examining bodies and psychiatrists.

\section{The study}

All 21 patients who took part in the clinical part of the membership section of the examination of the Royal College of Psychiatrists held at the Bethlem Royal Hospital in May 1989 were investigated. This hospital was one of the 11 national centres nominated to hold the examination on that occasion. Throughout the examination the patients were all treated in a standard way along guidelines suggested by the College. Thirty-one patients were initially approached to take part in the examination, two refused and two were later unavailable. Of the rest, six were held in reserve for use in the examination in case any of the others fell out at short notice. Those who did not take part in the examination were not interviewed for the study.

In the examination the patient spends one hour with the candidate. The candidate is then expected to discuss the history, diagnosis and management issues with two examiners for half an hour. The patient joins the candidate and examiners for about ten minutes during this half hour and may be questioned by examiners and/or candidate.

The examination took place over three consecutive days and patients were interviewed for the study within three weeks of the examination. These interviews were based on the same semi-structured protocol and were all conducted by one of the authors (RP). Each interview took between 30 to 45 minutes. No patient refused or needed persuading to answer questions.

One had commenced a course of ECT following the examination and had to be seen twice for the study, as her memory of taking part in the examination was not good the first time she was approached. Another became suspicious that her answers were going to be used to evaluate the candidate who had seen her in the examination. However she was easily reassured and it was not felt that her subsequent answers were affected by these beliefs. 
Two other patients were acutely psychotic, one displaying a similar mental state to that presented during the examination. The other had been discharged and readmitted since the examination because of a relapse. However both appeared to understand the interviewer's questions and did not give answers which were particularly atypical. None of the other patients' mental states had significantly changed between the time of the examination and the research interview.

No patient had been told about the research project before agreeing to take part in and attending the examination. While there had been no definite selection policy about gender, there had been attempts by the organisers to avoid 'professional patients' in keeping with College guidelines. The senior organiser and the organiser (CM) who selected the patients for the examination were also involved with the subsequent study. However the author who interviewed the patients for the study was not involved in their selection for the examination.

\section{Findings}

The 21 patients studied consisted of 14 men and seven women, of whom seven $(33 \%)$ had taken part in the Membership Examination before.

\section{Did they find the examination distressing?}

Six $(29 \%)$ patients found the experience a distressing one. Three were chiefly upset as a result of the candidates' history-taking. They particularly emphasised the unpleasantness of having to talk about distressing events which had happened in their past. Comments they made included:

"It was a long time since anyone had asked me anything going so far back. Bringing these terrible things up again made me feel very hopeless, as I began to wonder if the future was going to be anything like the past."

"Very hurtful things about the past came up - there were times I wanted to run out of the room."

"The doctor asked a lot of things about the beginning of my illness which I had hoped to forget and which distressed me."

The ward staff identified only one of these patients as returning to the ward in a distressed state. She was crying and had to be counselled for about an hour by staff. She received no additional medication nor was she seen by a doctor because of this incident. On subsequent questioning ward staff revealed to the researchers that they had felt strongly this patient should not have been selected for the examination, although they had not made the organisers aware of their reservations. Another of these patients admitted to crying privately in her room after the examination, and she was therefore certain that staff were unaware of this.

Other reasons for finding the experience unpleasant included severe anxiety before the examination. One patient declared that although the organisers had made it clear that it was the candidate being tested and not the patient, he had nevertheless become extremely anxious about saying everything correctly. He was concerned about not ruining the candidate's changes of passing. This anxiety was severe enough to cause him chest pains before and after the examination, symptoms which he had not communicated to ward staff at the time.

While not of such a severity to cause unpleasant anxiety, five other patients mentioned concerns about getting things right so as to help the candidate.

Another cause of distress was stated by one patient as her concern for the candidate's anxiety. While six others mentioned being surprised at how anxious the candidates were, this one was so concerned that she found the whole examination unpleasant. In a previous clinical membership examination in which the patient had taken part, she had encountered a candidate who was so distressed that she had had to counsel him. She stated he was so afraid he was completely unable to commence taking the history, and instead kept saying "right" and rocking forward on his chair in an attempt to reach for his pen to start writing. After he had done this repeatedly for almost five minutes the patient (who herself suffered from an obsessive-compulsive disorder) recognised he was caught in some sort of ritual and was completely overcome by nerves. She calmed the candidate down by placing a hand on his arm and said, "You have almost an hour to do this, it's plenty of time, on you go". The candidate then picked up his pen and started. Memories of this previous episode made this patient concerned for her candidate in the present examination in case history should repeat itself. As it was, she was relieved that the candidate this time did not have any of these problems. However, her memories ensured she remained nervous for the candidate until her session with him was over. Despite the relative smoothness with which things went this time her opinion of doctors had been permanently changed. She had before thought that doctors never experienced any anxiety. She was now excessively concerned about all staff, as she knew they might well have problems of their own, and often asked them how they were before relating her own problems.

Finally, one patient found the length of time spent waiting around "tedious" and "too long". He was particularly frustrated at the waiting period between being seen by the candidate and talking to the examiners.

Although 15 patients claimed not to find the examination 'unpleasant' only seven described it as 
positively enjoyable. Some reasons given for this included:

"I was only to pleased to help those who had helped me so much in the past."

"It was nice to be asked to do something important."

"It was fun to do as the focus was not on you as it usually is, the focus was on someone else."

"I found I could express myself more freely with the candidate than with the doctor on the ward."

One still clung to the notion that their comments to the candidate might have implications for their own treatment. This was despite instructions to the contrary from the organisers to all patients. This particular patient said:

"I always like to talk to doctors, you never know if they will uncover something which will help me. I knew the doctor in the exam was not my ward doctor, but they could write down anything new they found out and pass it on to my doctor and it would help me in the future."

\section{Would they wish to be considered for the examination again?}

Eight $(38 \%)$ said they would not like to take part again, most mentioning the amount of time it took up. Other reasons centred around the causes of distress mentioned before. Ten $(48 \%)$ said they would recommend it to another patient, but they realised many may not be suitable. All of the patients had a good grasp of the requirements of being articulate and not too unwell. Of the $11(52 \%)$ who would not recommend it, this was mostly because they did not want the responsibility should a patient 'behave incorrectly' in the examination. This hinted that most patients held notions that there was a 'right' way of behaving during the examination and a 'wrong' way. This was despite repeated assurances from the organisers that the patients were not under test.

Two patients would not recommend participating in the examination to anyone else as they declared they needed the money so badly, they did not want to do themselves out of business.

\section{What did they think the examination was for?}

Its purpose was explained to each patient before the examination by the organisers as being for doctors training to become more senior doctors in psychiatry, and it was organised by the Royal College of Psychiatrists.

However, from the investigation only $13(62 \%)$ patients claimed to know what the examination was for. The others had no idea at all and could only guess. Only one patient mentioned the College. Of those suggesting they knew what it was for, only five knew it was for doctors as opposed to the more commonly held belief that candidates were medical students.

Two thought it was for doctors learning about their particular condition. One thought it was a test of themselves and not of the doctors at all. Some had very unusual ideas and one declared, "The exam exists because psychiatry is a dark and mysterious thing and therefore it is to weed out quacks".

\section{Why did they think they were chosen?}

Eighteen patients $(86 \%)$ could suggest reasons why they thought they were chosen. Three had no idea at all and could not volunteer any possibilities.

Three thought they must be typical cases as that was what the organisers must be looking for. Interestingly none of them thought they were typical before the examination. Three others thought they must be 'special' or 'peculiar'. Two of them had felt this way about themselves before.

Two felt the long-term characters of their illnesses were the significant factor in their selection. Three thought it was because they were good communicators, for example one said: "I was picked because I am articulate and have a well known condition."

Two others felt it was the content of what they could talk about that was important, for example one said: "I had a lot of things to talk about, enough to last the hour."

One decided the examination was solely on his particular diagnosis. Another declared that as the ward staff found him a 'pain in the neck' generally, they had elected him for the examination to get him off the ward. One thought it was because he was not as ill as the others on the ward. Another said it was because he had volunteered for ward activities in the past.

Two used the fact they had been chosen for the examination as another piece of evidence for their delusional beliefs:

"I was chosen because of my pain." (This patient's pain was one of his many hypochondriacal delusions.)

"Because I am clever and know a lot about MI5 agents."

It was unclear in both of these cases whether being chosen had initiated the delusional thinking or whether it had simply been incorporated into a delusional system.

In general it did appear that selection had significant effects on patients' beliefs about themselves and their illnesses. In view of this it would be fascinating to know the feelings of those who were not selected. 


\section{Did they feel under any pressure to participate?}

A vast majority of nineteen $(91 \%)$ indicated they felt under no pressure to participate. This number were further aware that participation had no future implications for treatment. However a small minority, two or $9 \%$, were unaware they had had a choice. One felt he had been chosen and that was the end of the matter. The other simply felt he 'had to do it' as one of the requirements of in-patient status at the hospital. Despite this neither patient felt disgruntled at taking part.

\section{Why did they agree to take part?}

A sizeable minority, eight or $38 \%$, formulated their reasons for doing the exam in terms of trying to pay back the hospital, ward staff and doctors, for all the help they had been given. Another four, or $19 \%$, saw it in terms of being generally helpful with no specific notions of 'repayment'. One of these said he did it out of a sense of duty to other patients as well as staff.

A small number, two or $9 \%$, did it for enjoyment, while a further two did it to help themselves. One said: "When people ask a lot of questions about the past it helps you to see it more clearly yourself."

Only a minority of five $(24 \%)$ said they did it solely for the money.

\section{What did they feel about being paid?}

Not a single patient thought the $£ 6.00$ fee inadequate for their services. There was almost universal pleasure at its receipt. Only one patient refused to accept it, declaring: "Why should I benefit financially if it was in the interests of health?"

Although everyone had been briefed about the payment before the examination, two patients were surprised to be paid. A large majority, 16 or $76 \%$, claimed the money had been an irrelevant consideration in their decision to take part. This was despite one patient's point that: " $₫ 6.00$ is wealth indeed to an in-patient, it is three-quarters of what we would receive in a whole week in hospital."

One patient mistook the interviewer's question for an accusation and apologised for taking the money, volunteering to return it. Another had formed the impression that $£ 6.00$ was the going rate for being interviewed by doctors other than his own and asked the researcher for $£ 6.00$ at the end of the study interview.

\section{What did they think of the organisers?}

Almost unanimously the organisers were rated as treating the patients well. Only one felt otherwise and he could give no explicit reason for this. Another, although generally happy, complained there was too much sugar in his tea. Universally mentioned was the coffee and cigarettes provided for them. These seem to have great symbolic significance for patients. This lead to comments like:

"They gave us coffee and things in a way which you don't get on the ward."

"They treated you as a person, not a patient."

"They settled me down with coffee when I was frightened."

\section{What did they think of the examiners?}

Only one patient found the examiners unpleasant this was because he was disconcerted by their "changeable mood" during the time they were dealing with the candidate. While not finding them unpleasant five $(24 \%)$ commented on the examiners 'sterness' and 'strictness' and this contributed to them finding this encounter an 'intimidating' one. This led to comments like:

"They made me feel very nervous and that it was extremely important for me to get it right for the candidate."

"They looked very serious and this made me nervous."

"It was an intimidating experience, they felt very much as people in authority with power over me."

Three other patients $(14 \%)$ believed that an adversarial situation developed between the candidate and the examiners. They all felt a tendency to side with the candidate in this situation.

\section{What did they think of the candidate?}

In general the candidate had created a good impression. A large majority of patients $(19$, or $90 \%)$ thought their candidate was good and deserved to pass the examination. When asked for a comparison with their usual doctor some (four, or $19 \%$ ) went as far as saying the candidate was better than their current ward doctor. There was a general emphasis on the length of time spent by the candidate listening to the patient, though patients may not have realised how much this was part of the structure of the examination and not a decision of the candidate. Perhaps as a function of this length of time some (four, or $19 \%$ ) declared they had told things to their candidate which they had not said to their ward staff.

Comments included:

"She was very charming and totally disarmed me. She gave me almost an hour of her time while my ward doctor has barely five minutes for me."

"He seemed more experienced than my ward doctor, more probing in his questions." 
"He was very good, he got it all out of me, there were quite a few things I said to him which I had never told anyone before."

"I think he should have passed as he was very concerned about me."

Unfavourable comments were made of four candidates of whom three (14\%) were not assessed by the patients as deserving to pass the examination. These comments included:

"He didn't attend to me emotionally."

"He was a bundle of nerves, I felt sorry for him but doctors should not be like that."

"He was so nervous it made me worried."

"They are not interested in you as a person, they only talk to you to get through the exam, and it shows."

"He asked too many personal questions, particularly about things which did not matter."

Although one patient had no complaints about the candidate he had seen on this occasion, he did mention that in previous examinations he had felt harrassed by candidates. He said: "They had hassled me in the past. They often said, 'I haven't asked you about that, why are you telling me about that?' "

Did anything unexpected happen to the patients during the examination?

Only six (29\%) encountered situations during the examination which they felt they had not been prepared for beforehand. For five it was being physically examined by the candidate. As only six patients in total were examined, this surprise by the patients might hint at the dearth of physical examinations that psychiatric in-patients receive. Only one patient was distressed by the physical examination and she reported:

"He got up and started feeling around my neck asking if there was anything wrong with my thyroid. When I got back to the ward I began to worry that there might actually be something wrong with my thyroid which the ward doctor may have missed."

The only other unexpected event for a patient was encountering the examiners. He had forgotten the organisers' warning that this would happen.

\section{Did the examination change their attitudes?}

A large number $(10$, or $48 \%)$ felt taking part in the examination had changed their attitudes. Of these six $(29 \%)$ had changed their opinion of doctors. Encountering nervous candidates had made two patients realise for the first time that doctors were not immune from psychological problems themselves. This had shaken their faith in the profession to some extent but had also put doctors in a more human light.

Another had apparently found the evaluative atmosphere of the examination a different way of looking at the profession. This, coupled to the fact that she thought her candidate was particularly good, led her to decide her own doctor was "a bit slow". As a result of the examination she had started to develop her own notions of what was a good doctor. Similarly, another patient who had a female candidate but a male ward doctor decided she preferred female doctors. A third patient thought that as his candidate had been impressive compared to other doctors he had met, there must be a wide variation in doctors' competence.

One patient who had found the whole examination badly organised (he had thought he was being escorted to occupational therapy when he was brought to the examination centre) felt that the examination had confirmed his opinion that doctors "could not organise anything".

Another decided that as neither his ward doctor nor his candidate, of whom he had higher hopes, were any good he would have to rely more on himself. He declared, "Doing the examination made me realise that I am the best psychiatrist I will ever have."

One patient realised for the first time after doing the examination that the supply of psychiatrists was not an inevitable one. She now knew there was a selection procedure which many may not pass. Thus shortages could develop, she reasoned, and this made her more grateful for the help she had received in the past from psychiatrists. She resolved not to take them for granted in the future.

\section{Are patients and examiners looking for different things in psychiatrists?}

All the patients were asked the three qualities they valued most in psychiatrists. Almost invariably what the patients looked for seemed at variance with those qualities obviously assessed by the examination. For example, only one mentioned 'knowledge' while only one other valued 'experience'. The ability to listen was mentioned by eight $(38 \%)$ while a further five included listening 'sympathetically'. One was less demanding and only required the ability to 'appear as though listening'.

The ability to put patients at their ease was mentioned by three, with three others describing a general 'concerned' dimension, mentioning qualities like 'sympathy', 'empathy', 'concerned', and 'caring attitude'.

Other more unexpected comments were, 'cleanliness', 'pronunciation' and 'the ability to speak English', all valued by three different patients. 
Another valued the ability to ask 'questions which make you uncomfortable'. Somewhat mystical qualities seemed in demand by two patients, one mentioning 'serenity' and another 'the ability to touch you in a deep place'.

One patient's idiosyncratic response was the suggestion of 'clearness, feasibility and common sense'-which may have referred more to psychiatrists' theories rather than themselves.

\section{Did they have any suggestions for improving the examination?}

Six $(29 \%)$ had ideas for improving the examination and were pleased to be asked their opinion. Three of these suggested ways of making the candidates less nervous, as they felt this was a big problem and prevented the doctors performing at their best in front of the examiners. These suggestions were along the lines of the 'counselling' that patients had themselves received. This occurred before the examination when they were selected, and on the day itself.

One suggested candidates should be instructed to leave ten minutes for the patients to say whatever they wanted. This was because in this patient's experience of several examinations, candidates tended to decide too early what they thought the important issues were. Once this had been decided candidates' questions were too directive towards their early hypotheses. They did not allow patients time to bring up other important issues which the candidates' questions may have ignored. Candidates also became too anxious if patients began to 'ramble' when in fact the patients may have been trying to tell the candidate something important. Thus the patient suggested that ten minutes be set aside as part of the examination's structure to allow the patient to say anything they wanted to.

Another patient suggested giving candidates more time. She felt time pressure was an important cause of anxiety and that it should not matter if some candidates took slightly longer to reach a diagnosis or formulation as, unlike other branches of medicine, time pressure was not so crucial to psychiatry.

One patient felt the ability of a psychiatrist to give sensible advice clearly should be assessed as part of the examination. She felt there was a lamentable lack of this quality in doctors.

\section{Comment}

This survey of all patients taking part in a recent clinical psychiatric examination involved only 21 patients and is simply descriptive. However it reveals several findings which suggest intriguing results awaiting further research in this area. There are implications for those who organise examinations of this type as well as for psychiatry in general.
Those involved in setting clinical examinations should be interested in the finding that large numbers of those selected to take part had little idea or even erroneous misconceptions about their purpose. This was despite careful explanation by organisers who were rated almost unanimously by the patients as helpful.

Very few patients felt under pressure to participate or did so for the payment. They were, however, very grateful to receive this money and certainly did not regard it as a token gesture.

The examiners may be interested to know that most patients had high regard for their candidates. However, a small minority of patients did feel strongly that their candidate should not have passed. This raises a question concerning whether examiners should be made aware of the patients' opinions in their assessment of candidates.

Examiners and clinical psychiatrists may be concerned that a sizeable minority were distressed by the exam. This was often because of the candidate wanting to discuss upsetting past events, probably ignorant of their significance to the patient. Finding this unpleasant did not mean that these patients uniformly refused to take part in the examination again. One expressly said that he would be willing to do it again although he had been upset. This was because he thought it was such an important thing which helped doctors. This leads on to the uncovering of a deep well of respect for psychiatrists among patients approached for this investigation. It was an apparent reason for agreeing to take part in the examination.

The patients' own psychiatrists might be interested in those who admitted to revealing things about themselves to the candidate which they had not told their own doctors. Examiners might thus want to consider if there is any merit in appropriate information being fed back to ward staff. Several of the patients were affected by what the candidate said to them about their illnesses or themselves. In view of this, and some patients' distress, a form of patient debriefing might be suggested.

The examination these patients were taking part in did not appear to focus upon characteristics in psychiatrists which patients value. Although examiners assess how candidates interact with patients, whether the qualities sought may be very different to those the patients want needs investigation. Examiners certainly do not appear to formally test how good candidates are at giving advice to patients, which was one quality valued by patients in this study.

\section{Conclusion}

Definite conclusions that can be extrapolated to other populations from such an informal study with only 21 subjects are always difficult to defend. 
However, this study has served a purpose if it has suggested that what happens to patients during examinations and how they are affected by them needs more investigation. In a wider context this study also indicates that patients may differ from psychiatrists in their attitudes as to what makes a good practitioner and perhaps also how this should be assessed. Even if examining these questions is uncomfortable for doctors, is there merit in taking more account of patients' perceptions and concerns when considering the assessment of a psychiatrist's competence?

\section{Acknowledgements}

We would like to express our gratitude to Dr James Mackeith, the senior organiser of the clinical examination in this study, and also Professor P. Mullen.

\section{Reference}

McDonald, G. H., Daly, O. \& Cassidy, C. (1988) Organising the MRCPsych Part 1 Clinical Examination. Bulletin of the Royal College of Psychiatrists, 12, 227-229.

\section{GASKELL of Psychiatrists}

\section{Contemporary Themes in Psychiatry}

\section{A Tribute to Sir Martin Roth}

\section{Edited by}

Kenneth Davison \& Alan Kerr

519 pages, $£ 20$

ISBN 0902241281

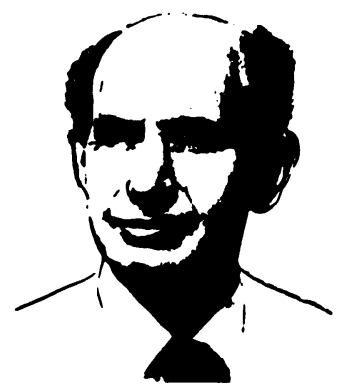

